\title{
Bundle Adherence of Intravenous Antibiotic Fluid Resuscitation and Vasopressor in Children with Severe Sepsis or Septic Shock
}

\author{
Clarice L Barboza ${ }^{1}$, Cristina OS Valete ${ }^{2}$, André RA da Silva ${ }^{3}$
}

\begin{abstract}
Objective: The aim of this study was to measure the effects of a bundle of interventions in children admitted with severe sepsis or septic shock in the first hour after diagnosis on mortality.

Materials and methods: A retrospective study was conducted at a pediatric intensive care unit (PICU) between January 2014 and January 2016. Three interventions (intravenous [IV] antibiotic, fluid boluses, and vasopressor administration) applied in the first hour of severe sepsis or septic shock diagnosis were analyzed according to their adherence rates. The main outcome was mortality. Odds ratios were calculated.

Results: Of a total of 530 PICU admissions, 105 patients met the criteria for sepsis, 53 (50.5\%) with severe sepsis and 52 (49.5\%) with septic shock. Seventy-two (68.6\%) patients received IV antibiotic within the first hour, 65 (61.9\%) received IV fluid bolus, and 55 (53.3\%) received a vasopressor drug. Fifty-two (49.5\%) patients received concomitant IV antibiotics and fluid bolus. Blood cultures were collected before IV antibiotic administration in 87 (82.9\%) out of 105 patients. Thirteen (12.4\%) patients died, 1 with severe sepsis and 12 with septic shock. In a univariate analysis, the odds ratios for death and IV antibiotic were 6.39 ( $p$ value $=0.081,95 \% \mathrm{Cl}=0.795-51.465$ ), 4.77 for fluid bolus between 21 and $40 \mathrm{~mL} / \mathrm{kg}$ ( $p$ value $=0.013,95 \% \mathrm{Cl}=1.395-16.336)$, and 3.23 for vasopressor administration $(p$ value $<0.0001,95 \% \mathrm{Cl}=1.734-6.018)$. In a multivariate analysis, the odds ratio of fluid bolus between 21 and $40 \mathrm{~mL} / \mathrm{kg}$ was 42.66 ( $p$ value $=0.005,95 \% \mathrm{Cl}=3.117-583.841)$ and noradrenaline use was 23.93 ( $p$ value $=0.010,95 \% \mathrm{Cl}=2.124-269.750$ ).

Conclusion: Adherence was observed for more than half of the single interventions as IV antibiotic, fluid resuscitation, and vasopressor administration in the first hour. The antibiotic administration alone was not associated with high mortality. Vasopressor administration was related to higher mortality but moderate fluid bolus was a protective factor associated with lower mortality.

Keywords: Antibiotic, Bundle, Fluid resuscitation, Pediatric intensive care unit, Sepsis.

Indian Journal of Critical Care Medicine (2020): 10.5005/jp-journals-10071-23336
\end{abstract}

\section{INTRODUCTION}

Severe sepsis and septic shock are critical conditions and important causes of death in children worldwide. ${ }^{1}$ The management and evolution of pediatric sepsis were assessed by Weiss et al., in a point prevalence study conducted in 26 different countries. In this report, common therapies for the sepsis treatment included antibiotic therapy (98\%), mechanical ventilation (74\%), vasoactive infusions (55\%), and corticosteroids (45\%). Hospital mortality was $25 \%$ and did not differ by age or between developed and resourcelimited countries. ${ }^{2}$

The Survival Sepsis Campaign (SSC) is one of the initiatives to standardize procedures and interventions with the purpose of reducing mortality in adult patients with sepsis, using the best available evidence. Some of these interventions were also recommended for children, although with different grade of evidence. ${ }^{3}$ Immediate recognition and treatment within the first hour after diagnosis with antimicrobials, fluid, and vasopressor administration are the core interventions that may change the prognosis., ${ }^{2,3}$

In an interventional, multicenter trial conducted in children from seven different large academic centers in Thailand who had been diagnosed with severe sepsis or septic shock, SSC bundles were applied and sepsis mortality was compared before and after intervention. Mortality was reduced significantly from $37 \% \pm$ $20.7 \%$, during the preintervention period, to $19.4 \% \pm 14.3 \%$, during the postintervention period $(p<0.001)$. The set of components
${ }^{1}$ Federal Fluminense University, Brazil

${ }^{2,3}$ Materno-Infantil Department, Federal Fluminense University, Brazil

Corresponding Author: André RA da Silva, Materno-Infantil Department, Federal Fluminense University, Brazil, Phone: +55 21 99854 1950, e-mail: aricardo@id.uff.br

How to cite this article: Barboza CL, Valete COS, da Silva ARA. Bundle Adherence of Intravenous Antibiotic Fluid Resuscitation and Vasopressor in Children with Severe Sepsis or Septic Shock. Indian J Crit Care Med 2020;24(2):128-132.

Source of support: Nil

Conflict of interest: None

included early disease diagnosis, optimum hemodynamic resuscitation, and timely antibiotic administration. ${ }^{4}$

Although the benefits are observed in adults, clinical studies have shown that only $8-30 \%$ of pediatricians have implemented a systematized approach to sepsis in their practice. ${ }^{5,6}$ Knowledge about the adherence to a bundle of early interventions in children with sepsis could provide substantial information to identify gaps in the initial approach and to evaluate the impact of these interventions on morbidity and mortality.

The aim of this study is to measure the effects of three interventions (intravenous antibiotic, fluid resuscitation, and vasopressor administration) in children admitted with severe sepsis or septic shock in the first hour after the diagnosis on mortality.

(c) The Author(s). 2020 Open Access This article is distributed under the terms of the Creative Commons Attribution 4.0 International License (https://creativecommons. org/licenses/by-nc/4.0/), which permits unrestricted use, distribution, and non-commercial reproduction in any medium, provided you give appropriate credit to the original author(s) and the source, provide a link to the Creative Commons license, and indicate if changes were made. The Creative Commons Public Domain Dedication waiver (http://creativecommons.org/publicdomain/zero/1.0/) applies to the data made available in this article, unless otherwise stated. 


\section{Materials and Methods}

\section{Study Design and Patients}

A retrospective descriptive study was performed in a cohort of children admitted in a pediatric intensive care unit (PICU), with severe sepsis or septic shock. The study was conducted in Prontobaby Children's Hospital, a private pediatric hospital in Rio de Janeiro city, Brazil, with ten-bed capacity. Patients were admitted from own emergency service or wards or referred from other hospitals, with clinical or surgical diseases. Until 2017, the hospital did not have a formalized protocol to treat patients with sepsis.

\section{Inclusion Criteria}

All patients admitted between January 1, 2014 and January 31, 2016 aged more than 1 month to less than 18 years with signs of severe sepsis or septic shock were included. Patients transferred to other services and/or admitted before 31 January 2016 but still in the unit after this date were excluded.

\section{Sample Size Calculation}

We used a sample size of convenience to analyze all patients with severe sepsis or septic shock in a 2-year follow-up.

\section{Severe Sepsis and Septic Shock Criteria}

Severe sepsis was defined as sepsis plus one of the following: cardiovascular organ dysfunction OR acute respiratory distress syndrome OR two or more other organ dysfunctions. Septic shock was defined as sepsis and cardiovascular organ dysfunction. ${ }^{7}$

\section{Data Extraction and Variables Analyzed}

Data were extracted from medical records. For each patient, the first moment when severe sepsis or septic shock should have been diagnosed was considered time zero. All interventions carried out in the resuscitation first hour were collected.

Demographic data collected included sex, age (months), pediatric risk of mortality score (PRISM), and in-hospital mortality. ${ }^{8}$

\section{Outcomes Evaluated}

The mortality after a bundle of interventions (antibiotic administration, fluid bolus administration, and vasopressor administration), applied in the first hour after severe sepsis or septic shock diagnosis, was the main outcome. Fluid boluses were categorized as follows: $<20 \mathrm{~mL} / \mathrm{kg}, 21-40 \mathrm{~mL} / \mathrm{kg}$, and $>40 \mathrm{~mL} / \mathrm{kg}$.

Table 1: Demographic profile of children admitted with severe sepsis or septic shock $(n=105)$

\begin{tabular}{lll}
\hline Variables & Median & $1^{\circ}$ and $3^{\circ}$ quartiles \\
\hline Age (months) & 37 & $9-111$ \\
PRISM* score & 3 & $1.9-9.1$ \\
\hline & Frequency (\%) & Cl 95\% \\
\hline Male gender & 59 & $46.2-65.9$ \\
Low weight & 9.5 & $4.0-15.6$ \\
Heart disease & 6.7 & $2.1-12.0$ \\
Neurologic disease & 10.5 & $4.7-16.8$ \\
Genetic disease & 11.4 & $5.3-18.0$ \\
Respiratory disease & 1.9 & $0.2-6.7$ \\
\hline
\end{tabular}

*Pediatric risk of mortality score

\section{Data Analysis}

First a descriptive variable analysis was performed using Excel files. It was assumed that the data were not normally distributed (Kolmogorov-Smirnov test). Medians, interquartile range, 95\% confidence intervals (Cls), Chi-square, Mann-Whitney tests, and odds ratios were calculated when required. Kappa coefficient was calculated to determine agreement among the categorical data: antibiotic administration and fluid bolus, septic shock and vasopressor administration. We used univariate analysis to explain the outcome: death/survival. The variables that presented a $p$ value of $<0.20$ were included in the model adjusted for age and gender. Forward technic was used to include variables one by one. Variables with a $p$ value of $<0.10$ remained in the model for final analysis. The results were considered statistically significant if the $p$ value was lower than $5 \%(p<0.05)$. Statistical analysis was processed using Stata 13.0 (Stata Corp LP).

\section{Ethics}

This study was approved by the Fluminense Federal University Institutional Ethics Committee (CAAE 65889617.2.000.5243).

\section{Results}

Of 530 admissions in the PICU within the study period, 105 children with diagnosis of severe sepsis or septic shock were identified and included for analysis, corresponding to 105 sepsis episodes. Patients' demographic data are listed in Table 1.

All 105 children had a suspected or proven infection and all of them received antibiotics during the hospital stay. Blood cultures were collected before IV antibiotic administration in $87 / 105(82.9 \%)$ of children. Positivity of blood cultures was $18 / 87$ (20.7\%).

Fifty-three (50.5\%) children had severe sepsis and 52 (49.5\%) had septic shock. Interventions done within the first hour are displayed in Table 2.

Of 55 patients who received a vasopressor, 47 fulfilled criteria for septic shock and 8 were classified as severe sepsis. Five of 52 (9.6\%) patients classified as septic shock did not receive any vasopressor. Norepinephrine was the first choice in 16 of 55 (29\%) patients who received a vasopressor.

Considering IV antibiotics and fluid bolus, 52 (49.5\%) patients received both interventions (Kappa coefficient $=0.12$, agreement $=54.3 \%, p$ value $=0.90)$.

The mean age (in months) in children who received vasopressor in the first hour was 50.3 and 68.7 in patients who received after 60 minutes $(p=0.02)$. The mean PRISM in children who received vasopressor in the first hour was 11.56 and 3.65 in children who received after this time period $(p<0.001)$.

Table 2: Interventions during the first hour in children with severe sepsis or septic shock $(n=105)$

\begin{tabular}{llll}
\hline Interventions & $N^{\circ}$ & Frequency (\%) & Cl 95\% \\
\hline Intravenous antibiotics & 72 & 68.6 & $54.8-73.8$ \\
Intravenous fluid bolus & 65 & 61.9 & $49.0-68.6$ \\
$\quad$ Up to $20 \mathrm{~mL} / \mathrm{kg}$ & 33 & 50.0 & $38.1-63.4$ \\
$21-40 \mathrm{~mL} / \mathrm{kg}$ & 20 & 30.8 & $19.9-43.5$ \\
$\quad$ More than $40 \mathrm{~mL} / \mathrm{kg}$ & 12 & 18.5 & $11.1-31.8$ \\
Vasopressor & 55 & 53.3 & $39.6-59.5$ \\
\hline
\end{tabular}


Table 3: Intravenous antibiotic, fluid bolus, vasopressor administration during the first hour in children with severe sepsis or septic shock $(n=105)$

\begin{tabular}{|c|c|c|c|c|c|c|}
\hline \multirow{2}{*}{$\begin{array}{l}\text { Interventions during } \\
\text { the first hour }\end{array}$} & \multicolumn{3}{|c|}{ Severe sepsis $(n=53)$} & \multicolumn{3}{|c|}{ Septic shock $(n=52)$} \\
\hline & Yes & No & $p$ value & Yes & No & $p$ value \\
\hline $\begin{array}{l}\text { Intravenous } \\
\text { antibiotics }\end{array}$ & 30 & 23 & 0.176 & 42 & 10 & $<0.001$ \\
\hline Intravenous fluid bolus & 24 & 29 & 0.335 & 41 & 11 & $<0.001$ \\
\hline Vasopressor & 8 & 45 & $<0.001$ & 47 & 5 & $<0.001$ \\
\hline
\end{tabular}

A comparison among the patients classified with severe sepsis and septic shock within the first hour who received or not IV antibiotic, fluid bolus, and a vasopressor is shown in Table 3.

Thirteen (12.4\%) patients died, being 1 with severe sepsis and 12 with septic shock. Univariate analysis results for outcome death in children with severe sepsis/septic shock is presented in Table 4. Odds ratios for bundle of interventions were as follows: $6.39(p$ value $=0.081,95 \% \mathrm{Cl}=0.795-51.465)$ for IV antibiotic, 2.24 ( $p$ value $=0.243,95 \% \mathrm{Cl}=0.577-8.700$ ) for IV fluid, and 3.23 for vasopressor administration ( $p$ value $<0.0001,95 \% \mathrm{Cl}=1.734-6.018$ ). In multivariate analysis, odds ratio for administration of volume between $21 \mathrm{~mL} / \mathrm{kg}$ and $40 \mathrm{~mL} / \mathrm{kg}$ was 42.66 ( $p$ value $=0.005,95 \%$ $\mathrm{Cl}=3.117-583.841)$. The other significant variables in univariate analysis were submitted to multivariate analysis and presented in Table 5.

\section{Discussion}

Systematic and standardized approach to sepsis is crucial to improve outcome and survival. Despite periodic updates of sepsis guidelines for different specialist societies, few reports are available in children describing intervention impact in this population. ${ }^{3,9}$

Sepsis is a common syndrome in critically ill children and in our casuistic represented almost one in five PICU admissions, but this varies according to the geographical region. de Souza et al., studying a sepsis prevalence in children admitted in 21 different South African PICUs, found a rate of $25.9 \%$ for severe sepsis and $19.8 \%$ for septic shock. ${ }^{10}$ Giuliano et al. reported a prevalence of $6.2 \%$ in European units and $7.7 \%$ in U.S. units, in a large pointprevalence study, involving a total of 411 PICUs. ${ }^{11}$

It was verified that almost $30 \%$ of our patients had at least one comorbidity that is compatible with previous articles. The prevalence of comorbidities in pediatric sepsis ranges from $6 \%$ to $40 \%$, being respiratory diseases the most commonly reported. ${ }^{2,11}$

Identification of infectious agents in patients with sepsis through culture collection according to the suspected sites is a key point to determine the best treatment for patients, making the de-escalation of empiric treatment usually prescribed possible. ${ }^{3}$ In this study, all patients received empiric antibiotics being positivity of blood cultures similar to what was reported by SPROUT study (15\%). ${ }^{2}$

Intravenous antibiotic administration within the first hour after sepsis diagnosis is preconized as strong recommendation by adult guidelines and verified in $68.6 \%$ of our patients. These data are similar (67.7\%) to those described by Evans et al. in an evaluation of 1,179 pediatric patients of New York state and superior (31\%) to those reported by Creedon and Cols in 135 children with sepsis in Chicago, USA, and for Collaborative Group, 2012, that found a $59.5 \%$ of adherence rate for antibiotic administration within
Table 4: Univariate analysis for outcome death in children with severe sepsis or septic shock $(n=105)$

\begin{tabular}{|c|c|c|c|}
\hline Variables & Odd ratio & $\mathrm{Cl} 95 \%$ & $p$ value \\
\hline Heart disease & 3.16 & $0.546-18.309$ & 0.199 \\
\hline Neurologic disease & 0.68 & $0.801-5.825$ & 0.728 \\
\hline Genetic disease & 1.49 & $0.288-7.712$ & 0.480 \\
\hline Respiratory disease & 6.29 & $3.870-12.383$ & $<0.001$ \\
\hline Low weight & 1.90 & $0.358-10.162$ & 0.448 \\
\hline PRISM score & 1.09 & $1.036-1.154$ & 0.001 \\
\hline Tachycardia/bradycardia & 2.52 & $0.306-20.838$ & 0.389 \\
\hline Tachypnea/bradypnea & 4.00 & $0.492-32.464$ & 0.194 \\
\hline Arterial hypotension & 17.83 & $2.223-143.086$ & 0.007 \\
\hline Oliguria & 7.77 & $2.233-27.089$ & 0.001 \\
\hline Septic shock & 15.60 & $1.946-125.022$ & 0.010 \\
\hline Leukocytosis/leukopenia & 6.53 & $3.647-11.721$ & $<0.001$ \\
\hline $\begin{array}{l}\text { Infection suspected/ } \\
\text { comproved }\end{array}$ & 0.266 & $0.022-3.168$ & 0.295 \\
\hline Metabolic acidosis & 4.14 & $1.183-14.536$ & 0.026 \\
\hline $\begin{array}{l}\text { Increase in blood lactate } \\
\text { levels }\end{array}$ & 4.80 & $1.427-16.143$ & 0.011 \\
\hline $\begin{array}{l}\text { Antibiotic use within the } \\
\text { first hour }\end{array}$ & 6.39 & $0.795-51.465$ & 0.081 \\
\hline $\begin{array}{l}\text { Antibiotic de-escalation } \\
\text { within } 72 \text { hours }\end{array}$ & 6.84 & $3.825-12.251$ & 0.194 \\
\hline Positive blood culture & 1.54 & $0.378-6.268$ & 0.547 \\
\hline $\begin{array}{l}\text { Intravenous fluid use within } \\
\text { the first hour }\end{array}$ & 2.24 & $0.577-8.700$ & 0.243 \\
\hline $\begin{array}{l}\text { Intravenous fluid up to } \\
20 \mathrm{~mL} / \mathrm{kg}\end{array}$ & 0.15 & $0.019-1.256$ & 0.081 \\
\hline $\begin{array}{l}\text { Intravenous fluid between } \\
21 \text { and } 40 \mathrm{~mL} / \mathrm{kg}\end{array}$ & 4.77 & $1.395-16.336$ & 0.013 \\
\hline $\begin{array}{l}\text { Intravenous fluid } \\
>40 \mathrm{~mL} / \mathrm{kg}\end{array}$ & 2.46 & $0.578-10.462$ & 0.223 \\
\hline Crystalloid use & 2.34 & $0.604-9.096$ & 0.218 \\
\hline Vasopressor administration & 3.23 & $1.734-6.018$ & $<0.001$ \\
\hline Noradrenaline as first option & 19.4 & $4.434-63.652$ & $<0.001$ \\
\hline
\end{tabular}

Table 5: Multivariate analysis of variables associated to death in children with sepsis $(n=105)$

\begin{tabular}{lccl}
\hline Variables & Odds ratio & p value & Cl 95\% \\
\hline PRISM score & 1.08 & 0.090 & $0.980-1.191$ \\
Arterial hypotension & 16.46 & 0.052 & $0.976-277.818$ \\
Intravenous fluid between & 42.66 & 0.005 & $3.117-583.841$ \\
$\begin{array}{l}21-40 \mathrm{~mL} / \mathrm{kg} \\
\text { Noradrenaline use }\end{array}$ & 23.93 & 0.010 & $2.124-269.750$ \\
\hline
\end{tabular}


the first hour, in four different PICUs from Shanghai, China. ${ }^{12-14}$ Although early administration of antibiotics has been associated with better outcomes in adult studies, this association was not found in our cohort. ${ }^{15}$ It seems that antibiotics administration in children within 3 hours after diagnosis did not lead to increased mortality. ${ }^{16,17}$ It is not suggested that antibiotics can be delayed in children with severe sepsis or septic shock, due to the limitations of this study.

Another important key intervention in pediatric sepsis is fluid administration as rapidly as possible. ${ }^{18}$ In this casuistic, IV fluid bolus was administered in $61.9 \%$ of the patients. On the contrary, a multicenter study, using an electronic survey applied in pediatric and nonpediatric emergency specialists of 14 Latin countries, found an overall adherence rate of $32 \%$ for infusion from $40 \mathrm{~mL} / \mathrm{kg}$ to $60 \mathrm{~mL} / \mathrm{kg}$ within 30 minutes, in cases of septic shock. ${ }^{19}$ Possible barriers to improve adherence to fluid administration include lack of early shock recognition, lack of vascular access, and delay in pharmacy processing and delivery. ${ }^{20,21}$ Unfortunately, none of these items were assessed in this study.

Lack of response in septic shock after fluid resuscitation requires vasopressor administration. ${ }^{3,9}$ It was observed in this paper that almost all the patients with shock septic criteria received a vasopressor, according to current recommendations. ${ }^{22}$

Considering antibiotic and fluid bolus administration within the first hour, almost half of the patients received both interventions. These results are superior (24.9\%) to those described by Evans and Cols in a similar analysis of adherence to a bundle for pediatric sepsis. ${ }^{12}$

Mortality found in this study (12.4\%) was similar to other studies. ${ }^{13,23}$ Moreover, a protective association was found between death and any fluid bolus within the first hour and fluid bolus $21-40 \mathrm{~mL} / \mathrm{kg}$, suggesting that moderate fluid boluses within the first hour could be beneficial. More fluid bolus was not associated with better outcome. This was also observed by Paridon and colleagues analyzing 79 patients in a single center. ${ }^{24}$ It has been suggested that higher fluid volumes are associated with cardiovascular collapse and worse outcomes.

Vasopressor administration was associated with a higher mortality, and this result may reflect higher severity scores, as those who received a vasopressor were younger and had higher PRISM scores. Although evidence for timing of vasopressor administration in children are weak, it is not suggested that such drugs cause harm. Paridon et al. did not find association between timing of vasopressor administration and outcomes. ${ }^{24}$

This study has limitations. First, the research was conducted in a single-center cohort, and it could reflect a specific local situation in managing severe sepsis and septic shock. Second, we used a limited sample size, although multivariate analysis was performed to identify significant associations between interventions and impact on mortality. Third, as retrospective analysis was performed, it is possible that some patients could have received some interventions before admission and not reported in medical files, thus interfering in the final analysis.

In conclusion, despite the lack of a standardized protocol for sepsis management in our unit, adherence was verified for more than half for single interventions such as IV antibiotic, fluid resuscitation, and vasopressor administration in the first hour. Antibiotic administration alone was related to high mortality, although without statistical significance. Vasopressor administration was related to higher mortality but moderate fluid bolus was a protective factor associated with lower mortality.
Efforts need to be put to improve bundle adherence and confirm the best moment for antibiotic administration.

\section{References}

1. Santschi M, Leclerc F. Management of children with sepsis and septic shock: a survey among pediatric intensivists of the Réseau MèreEnfant de la Francophonie. Ann Intensive Care 2013;3(1):1-7. DOI: 10.1186/2110-5820-3-7.

2. Weiss SL, Fitzgerald JC, Pappachan J, Wheeler D, JaramilloBustamante JC, Salloo A, et al. Global epidemiology of pediatric severe sepsis: the sepsis prevalence, outcomes, and therapies study. Am J Respir Crit Care Med 2015;191(10):1147-1157. DOI: 10.1164/ rccm.201412-23230C.

3. Rhodes A, Evans LE, Alhazzani W, Levy MM, Antonelli M, Ferrer $R$, et al. Surviving sepsis campaign: international guidelines for management of sepsis and septic shock: 2016. Intensive Care Med 2017;43(3):304-377. DOI: 10.1007/s00134-017-4683-6.

4. Samransamruajkit R, Uppala R, Pongsanon K, Deelodejanawong J, Sritippayawan S, Prapphal N. Clinical outcomes after utilizing surviving sepsis campaign in children with septic shock and prognostic value of initial plasma NT-proBNP. Indian J Crit Care Med 2014;18(2):70-76. DOI: 10.4103/0972-5229.126075.

5. Inwald DP, Tasker RC, Peters MJ, Nadel S. Emergency management of children with severe sepsis in the United Kingdom: the results of the Paediatric Intensive Care Society sepsis audit. Arch Dis Child 2009;94(5):348-353. DOI: 10.1136/adc.2008.153064.

6. Launay E, Gras-Le Guen C, Martinot A, Assathiany R, Blanchais T, Mourdi N, et al. Suboptimal care in the initial management of children who died from severe bacterial infection: a population-based confidential inquiry. Pediatr Crit Care Med 2010;11(4):469-474. DOI: 10.1097/PCC.0b013e3181ce752e.

7. Goldstein B, Giroir B, Randolph A, International Consensus Conference on Pediatric Sepsis. International pediatric sepsis consensus conference: definitions for sepsis and organ dysfunction in pediatrics. Pediatr Crit Care Med 2005;6(1):2-8. DOI: 10.1097/01. PCC.0000149131.72248.E6.

8. Costa GA, Delgado AF, Ferraro A, Okay TS. Application of the pediatric risk of mortality (PRISM) score and determination of mortality risk factors in a tertiary pediatric intensive care unit. Clinics (Sao Paulo) 2010;65(11):1087-1092. DOI: 10.1590/S1807-59322010001100005.

9. Dellinger RP, Carlet JM, Masur H, Gerlach H, Calandra T, Cohen J, et al. Surviving sepsis campaign guidelines for management of severe sepsis and septic shock. Crit Care Med 2004;32(3):858-873. DOI: 10.1097/01.CCM.0000117317.18092.E4.

10. de Souza DC, Shieh HH, Barreira ER, Ventura AM, Bousso A, Troster EJ, et al. Epidemiology of sepsis in children admitted to PICUs in South America. Pediatr Crit Care Med 2016;17(8):727-734. DOI: 10.1097/ PCC. 0000000000000847 .

11. Giuliano Jr JS, Markovitz BP, Brierley J, Levin R, Williams G, Lum LC, et al. Comparison of pediatric severe sepsis Managed in U.S. and European ICUs. Pediatr Crit Care Med 2016;17(6):522-530. DOI: 10.1097/PCC.0000000000000760.

12. Evans IVR, Phillips GS, Alpern ER, Angus DC, Friedrich ME, Kissoon N, et al. Association between the New York sepsis care mandate and in-hospital mortality for pediatric sepsis. JAMA 2018;320(4):358-367. DOI: 10.1001/jama.2018.9071.

13. Creedon JK, Vargas S, Asaro LA, Wypij D, Paul R, Melendez E. Timing of antibiotic administration in pediatric sepsis. Pediatr Emerg Care 2018. DOI: 10.1097/PEC.0000000000001663.

14. Collaborative Group for the Study of Sepsis in PICUs in Shanghai Area. Hospital epidemiology, management and outcome of pediatric sepsis and severe sepsis in 4 PICUs in Shanghai. Zhonghua Er Ke Za Zhi 2012;50(3):172-177.

15. Puskarich MA, Trzeciak S, Shapiro NI, Arnold RC, Horton JM, Studnek $\mathrm{JR}$, et al. Association between timing of antibiotic administration and 
mortality from septic shock in patients treated with a quantitative resuscitation protocol. Crit Care Med 2011;39(9):2066-2071. DOI: 10.1097/CCM.0b013e31821e87ab.

16. Weiss SL, Fitzgerald JC, Balamuth F, Alpern ER, Lavelle J, Chilutti $M$, et al. Delayed antimicrobial therapy increases mortality and organ dysfunction duration in pediatric sepsis. Crit Care Med 2014;42(11):2409-2417. DOI: 10.1097/CCM.0000000000000509.

17. Kawasaki T. Update on pediatric sepsis: a review. J Intensive Care 2017;5:47. DOI: 10.1186/s40560-017-0240-1.

18. WHO Pocket Book of Hospital Care for Children: Guidelines for the Management of Common IIInesses with Limited Resources. Available from: https://www.who.int/maternal child adolescent/documents/ child_hospital_care/en/, Accessed on 09 August 2019.

19. Kohn-Loncarica GA, Fustiñana AL, Jabornisky RM, Pavlicich SV, Prego-Pettit J, Yock-Corrales A, et al. How are clinicians treating children with sepsis in emergency departments in Latin America? An International Multicenter Survey. Pediatr Emerg Care 2019. DOI: 10.1097/PEC.0000000000001838.
20. Oliveira CF, Nogueira de Sá FR, Oliveira DS, Gottschald AF, Moura $J D$, Shibata $A R$, et al. Time and fluid-sensitive resuscitation for hemodynamic support of children in septic shock. Pediatr Emerg Care 2008;24(12):810-815. DOI: 10.1097/PEC.0b013e31818e9f3a.

21. Paul R, Melendez E, Wathen B, Larsen G, Chapman L, Wheeler DS, et al. A quality improvement collaborative for pediatric sepsis: lessons learned. Pediatr Qual Saf 2017;3(1):e051. DOI: 10.1097/ pq9.0000000000000051.

22. Prusakowski MK, Chen AP. Pediatric sepsis. Emerg Med Clin North Am 2017;35(1):123-138. DOI: 10.1016/j.emc.2016.08.008.

23. Fitzgerald JC, Weiss SL, Kissoon N. 2016 update for the Rogers' textbook of pediatric intensive care: recognition and initial management of shock. Pediatr Crit Care Med 2016;17(11):1073-1079. DOI: 10.1097/PCC.0000000000000942.

24. Paridon BM, Sheppard C, Garcia GG, Joffe AR, Alberta Sepsis Network. Timing of antibiotics, volume, and vasoactive infusions in children with sepsis admitted to intensive care. Crit Care 2015;19:293. DOI: 10.1186/s13054-015-1010-x. 